\title{
Quality of life of parents with children living at home: when one parent has cancer
}

\author{
Stacey M. Gazendam-Donofrio • Harald J. Hoekstra • \\ Winette T.A. van der Graaf • Elizabeth Pras • \\ Annemieke Visser • Gea A. Huizinga • \\ Josette E.H.M. Hoekstra-Weebers
}

Received: 26 January 2007 / Accepted: 11 June 2007 / Published online: 3 July 2007

(C) Springer-Verlag 2007

\begin{abstract}
Goals of work This study examined the quality of life (QoL) of cancer patients diagnosed 1-5 years previously and their spouses, with children 4-18 years living at home. Relationships between parents' QoL and the children's functioning were explored.

Patients and methods 166 cancer patients and their spouses provided information on their QoL (RAND-36) and on their children's functioning (Child Behavior Checklist).

Main results Male and female patients scored similarly to a norm population on five domains. Patients' QoL was

\author{
S. M. Gazendam-Donofrio • J. E. Hoekstra-Weebers ( $₫)$ \\ Wenckebach Institute, \\ University Medical Center Groningen, \\ P.O. Box 30001, 9700 RB Groningen, The Netherlands \\ e-mail: j.hoekstra-weebers@psb.umcg.nl

\section{H. J. Hoekstra} \\ Department of Surgical Oncology, University Medical Center \\ Groningen, University of Groningen, \\ Groningen, The Netherlands

\section{W. T. van der Graaf} \\ Medical Center, \\ Nijmegen, the Netherlands

\section{E. Pras} \\ Department of Radiation Oncology, University Medical Center \\ Groningen, The Netherlands
}

Department of Medical Oncology, Radboud University Nijmegen

Groningen, University of Groningen,
\end{abstract}

\author{
A. Visser · G. A. Huizinga · J. E. Hoekstra-Weebers \\ Department of Health Psychology, University Medical Center \\ Groningen, University of Groningen, \\ Groningen, The Netherlands \\ J. E. Hoekstra-Weebers \\ Comprehensive Cancer Center North-Netherlands, \\ Groningen, The Netherlands
}

clinically relevantly and/or statistically lower on social functioning, role limitations because of physical problems, and vitality than the norm. Male spouses' QoL was comparable to the norm. However, female spouses reported better physical functioning but more social problems. QoL varied according to type of cancer, treatment intensity, and recurrence. Using the QoL composite scores, a significant relationship was found between patients' psychosocial and physical functioning and spouses' psychosocial functioning. Patients' psychosocial functioning correlated moderately strongly to weakly with their reports of their younger children's and adolescents' functioning; physical functioning correlated only weakly with adolescents' functioning. The patients' functioning related weakly to moderately strongly to adolescents' self-reports of functioning. Spouses' psychosocial functioning weakly related to their and adolescents' reports of adolescents' functioning.

Conclusions Cancer patients' QoL 1-5 years after diagnosis was decreased in three of eight domains; their spouses seem to be doing well. Parents' physical and psychosocial functioning related weakly to moderately strongly to their children's functioning, depending on the child's age and information source. The patients' functioning related more strongly to the children's functioning than the spouses' did.

Keywords Quality of life · Parental cancer Patient . Spouse $\cdot$ Children

\section{Introduction}

The impact of cancer on a patient's psychosocial functioning has received much attention in the literature over the past decades. It is generally acknowledged that a patient's 
quality of life (QoL) decreases while they are battling their illness. Problems in QoL tend to diminish over time as a patient responds to treatment. However, a significant percentage of patients continues to experience clinically elevated levels of problems requiring professional treatment [40]. Furthermore, a growing number of studies provides evidence that cancer patients' spouses develop problems affecting their QoL [14, 17, 21, 23, 25, 27]. Spouses have reported psychological and physical distress, which have been found to correlate with the patient's dysfunction [17].

However, the majority of studies examine patients and spouses in later adulthood [5, 6, 13, 25, 29]. Most incidences of cancer occur in older adults. According to the Dutch Comprehensive Cancer Center's database, $70 \%$ of all new incidences of cancer in The Netherlands in 2003 occurred in patients more than the age of 60 [11]. Parental cancer in younger families may be a more serious stressor than in later phases of life, as illness and death in later adulthood could be considered more natural or normative [37, 39]. It has been shown that older cancer patients report less anxiety and depression and better QoL than younger adult patients [26]. Couples in an earlier life phase with young children and adolescents at home lead busy lives. They juggle childrearing responsibilities and the demands of sustaining a healthy marriage with trying to meet the individual (career) needs of each partner [28]. In the case of families with parental cancer, parents have the added strain of their loved one being ill. Additionally, their stress may be confounded when the patient may not be able to work or take care of the children as well as before the onset of the disease.

Only a few studies have examined the impact of cancer on the functioning of all members in families in this phase of life. In our previous investigations of families confronted with parental cancer, the main focus has been on the children's psychological well being [20,36]. Results have shown clinically elevated levels of distress in $35 \%$ of adolescent daughters and $21 \%$ of adolescent sons [20] and higher levels of emotional problems in adolescent daughters and elementary school-aged sons of cancer patients [36]. It is possible that the children's emotional and behavioral functioning, which may be affected by their parent's cancer, affects how the parents function.

The current study had four main aims. The first aim was to examine health-related QoL of patients and spouses in families with young children 1-5 years after diagnosis. We hypothesized that cancer patients and their spouses' QoL would be lower than that of a norm group and that QoL would differ as a function of health status and gender (i.e., which parent was ill: the mother or father). Based on literature [30], we expected to find that female patients reported the lowest QoL, followed by female partners, male patients, and male partners. The second aim was to examine the effect of illness-related variables (time since diagnosis, recurrence, treatment intensity, and type of cancer) on parents' QoL. We expected that patients and spouses would report more problems more shortly after diagnosis, when confronted with recurrence of cancer and when treatment was intense and, also, that QoL would differ depending on type of cancer. Our third aim was to examine relationships between patient's and spouse's QoL; we hypothesized that they would be significantly related. Finally, the fourth aim was to explore possible relationships between the parents' QoL and the children's emotional and behavioral functioning.

\section{Materials and methods}

Procedure

Both hospitalized cancer patients and those being treated or seen for follow-up visits at the outpatient clinic of the University Medical Center Groningen between January 2001 and February 2003 were approached by surgical, medical, and radiation oncologists and oncology nurses. Patients were eligible for the study if they were diagnosed with cancer 1-5 years before study entry and had children between the ages of 4 and 18 years at the time of parent's diagnosis who resided or had frequent contact with the diagnosed parent. Furthermore, both parents and children needed to be fluent in Dutch. A family could participate in the study if the patient and at least one child agreed to participate. Physicians and oncology nurses offered all eligible patients and spouses written information plus an information brochure adapted for the children. Informed consent was obtained from each family member separately, as regulated by the Medical Ethical Committee of the University Medical Center Groningen. After obtaining informed consent, researchers mailed packages with questionnaires and prepaid return envelopes to each family member. Cancer patients, spouses, and children were instructed to fill in questionnaires independently of each other and to not discuss their answers.

Instruments

Demographic data was gathered on: age, gender, level of education, length of relationship, number of children living at home, and who the primary caregiver in the family is. Patients provided information about when they were diagnosed, their type of cancer, treatment intensity, and recurrence. Education was measured on a seven-point scale from (1) elementary school only to (7) university degree.

The eight subscales and two component summary scores of the Dutch translation of the RAND-36 were used to measure QoL $[8,31,38]$. Scores on the subscales can range 
from 0 to 100 , with higher scores indicating better functioning. When comparing patients and spouses to a reference group, norm scores were used from the Dutch manual for the RAND-36 [31]. The manual provides mean scores from a random sample of 1,063 people between the ages of 18 and $89(65 \%$ women, age $M=44.1)$ from the population register of a municipality in The Netherlands. Norm scores are provided for each subscale for the entire sample and for men and women separately. Summary scores report physical functioning and psychosocial functioning and are standardized with a mean of 50 and a standard deviation of 10 . The reliability and validity of the RAND-36 has been supported in a wide number of international and national studies [8, 32, 33]. Cronbach's alphas in this study on the eight subscales ranged between 0.72 and 0.90 for patients and 0.78 and 0.90 for partners.

To investigate how parents' QoL related to the children's functioning, parents were asked to complete the 120-item Child Behavior Checklist (CBCL) [1, 34]. Adolescents also completed the 102-item Youth Self-Report (YSR) [2, 35]. In this study, the internalizing (emotional functioning), externalizing (behavioral functioning), and total problem (total of internalizing, externalizing, and cognitive problems) scales were used to provide a picture of the problems occurring in the children of parents diagnosed with cancer. The CBCL's and YSR's reliability and validity have been supported in a great number of studies. In this study, Cronbach's alphas for the internalizing, externalizing, and total problem scales ranged from 0.84 to 0.94 for reports from patients, spouses, and adolescent children.

\section{Analysis}

In our analyses, a single variable was created to define treatment intensity. Patients were grouped into two categories based on the clinical expectation that surgical treatment alone (nonintense treatment) would be less distressing to the family because of less time away from home and fewer visible side effects. Other single-modal (chemo-, radiotherapy) and multimodal treatments (combination of surgery, chemotherapy, radiotherapy, hormone, or immunotherapy) were defined as intense. Time since diagnosis was calculated by subtracting the date on which the patient filled in the questionnaires from the date they were diagnosed. Descriptive analyses were performed on demographic information. Comparisons between patients, spouses, and the reference group were investigated using independent $t$ tests. Results were corrected for the number of tests performed with a Bonferroni correction for multiple comparisons; $p$ values less than or equal to 0.0015 were considered significant ( 0.05 of 32 tests). To assess clinical relevance, effect sizes (ESs) were calculated by dividing the difference between means by the square root of the average of the squared standard deviations [10]. ESs between 0.20 and 0.49 were considered small, 0.50 and 0.79 medium, and $\geq 0.80$ large [10]. We considered that ESs greater than or equal to 0.50 indicated a clinically relevant difference [24]. A single variable was created to describe parents' gender and health status (ill mothers, ill fathers, healthy mothers, and healthy fathers). One-way analyses of variance (ANOVAs) with a Bonferroni post-hoc test were used to compare QoL of patient and spouse as a function of gender and health status. After the correction for multiple tests was applied, $p$ values less than or equal to 0.005 were considered significant ( $p=0.05$ of ten tests). In analyses of QoL as a function of type of cancer, only groups of ten or more patients were included. An ANOVA and a KruskalWallis test (some patient groups were small) were performed to compare patients' and spouses' QoL as a function of type of cancer. After the correction for multiple tests was applied, $p$ values less than or equal to 0.005 were considered significant ( $p=0.05$ of ten tests). The two QoL composite scores (physical summary score and psychosocial summary score) were used in correlational analyses to explore relationships between parents' QoL and between each parent's QoL and the children's problems, with separate analyses for elementary school-aged (4-10 years) and adolescent (11-18 years) children. Pearson's productmoment correlation coefficients were calculated; correlations with a coefficient less than 0.30 were considered weak, $0.30-0.50$, moderately strong, and greater than 0.50 , strong [10].

\section{Results}

Participants

A total of 476 families were approached for the study. Two hundred and nine agreed to participate (44\%), including 336 children, with an average of 2.3 children per family. Because this study focused on couples, we selected data from families where both patient and spouse filled in questionnaires, resulting in a database of 166 couples and 304 children. Table 1 summarizes the demographic information. The majority of cancer patients in this study were women (78\%). Patients were diagnosed with various types of cancer (Table 3), including breast (52\%), gynecological (10\%), hematological (9\%), skin (9\%), urological (6\%), soft tissue and bone tumors $(6 \%)$, head/neck $(4 \%)$, gastrointestinal $(3 \%)$, and central nervous system $(1 \%)$. Fourteen percent of patients had undergone nonintense treatment $(N=23)$, and $86 \%$ had undergone intense treatment $(N=143)$.

There were no significant differences between participating and nonparticipating parents regarding patient's gender, type of cancer, or time since diagnosis. Of the 
Table 1 Demographics

\begin{tabular}{|c|c|c|c|}
\hline & Patient & Spouse & Children \\
\hline Mean age in years (SD) & $\begin{array}{l}44.7 \\
(4.9)\end{array}$ & $\begin{array}{l}45.8 \\
(6.4)\end{array}$ & $\begin{array}{c}14.5 \\
(4.2)\end{array}$ \\
\hline Range & $\begin{array}{r}32.8- \\
57.8\end{array}$ & $\begin{array}{r}31.2- \\
65.7\end{array}$ & $4-23$ \\
\hline Gender, $N(\%)$-female & $\begin{array}{l}129 \\
(78)\end{array}$ & $\begin{array}{l}37 \\
(22)\end{array}$ & $167(55)$ \\
\hline Gender, $N(\%)$-male & $\begin{array}{l}37 \\
(22)\end{array}$ & $\begin{array}{l}129 \\
(78)\end{array}$ & $137(45)$ \\
\hline $\begin{array}{l}\text { Mean length of relationship in years } \\
\text { (SD), range } 4-41\end{array}$ & $\begin{array}{l}21.3 \\
(6.6)\end{array}$ & & \\
\hline Mean education level (SD), range 1-7 & $\begin{array}{l}3.8 \\
(1.6)\end{array}$ & $\begin{array}{l}3.9 \\
(1.8)\end{array}$ & \\
\hline $\begin{array}{l}\text { Mean number of children per couple, } \\
\text { range }=1-6\end{array}$ & 2.3 & & \\
\hline \multicolumn{4}{|l|}{ Primary caregiver in family, $N(\%)$} \\
\hline Mother & $\begin{array}{l}105 \\
(63)\end{array}$ & & \\
\hline Father & $5(3)$ & & \\
\hline Both parents & $\begin{array}{l}54 \\
(33)\end{array}$ & & \\
\hline Other & $2(1)$ & & \\
\hline Mean time since diagnosis in years (SD) & $\begin{array}{l}2.76 \\
(1.2)\end{array}$ & & \\
\hline Treatment intensity—nonintense, $N(\%)$ & $\begin{array}{l}23 \\
(14)\end{array}$ & & \\
\hline Treatment intensity-intense, $N(\%)$ & $\begin{array}{l}143 \\
(86)\end{array}$ & & \\
\hline Recurrence of cancer N (\%) & $\begin{array}{l}36 \\
(22)\end{array}$ & & \\
\hline
\end{tabular}

nonparticipants, $22 \%(N=59)$ declined because of reasons directly related to the parents (e.g., parents had moved on with their lives or were too emotionally distressed). Reasons related to the children (e.g., children were not interested, children had not been informed of parent's illness) were given as the explanation for not wanting to be included in $20 \%(N=53)$ of nonparticipating families. Twenty-five percent $(N=67)$ mentioned a variety of reasons, including another illness in the family or the parents' or children's busy-ness. The remaining 33\% ( $N=$ 88) did not provide an explanation.

Patients' and spouses' QoL in comparison with the norm

Results are summarized in Table 2. Clinically relevant ESs were found for male patients' social functioning, role limitations because of physical problems, and vitality. Both male and female patients scored statistically significantly lower QoL than the norm on one subscale: vitality. Female patients additionally scored lower on two subscales: social functioning and role limitations because of physical problems.

Clinically relevant ESs were found for female spouses' physical functioning and social functioning. Female spouses reported statistically significantly higher scores than the norm on physical functioning. They also scored statistically significantly lower on social functioning than the norm.

Effects of health status and gender, time since diagnosis, recurrence, treatment intensity, and type of cancer on QoL

Parents' health status and gender had a statistically significant effect on parents' physical summary score. A statistically significant effect was also found on parents' physical functioning, role limitations because of physical problems, vitality, and general health perception (Table 2).

A Bonferroni post-hoc test revealed the following. On the physical summary score, female patients scored lower than male spouses $(p<0.001)$, and male patients scored lower than female and male spouses ( $p<0.001$ for both). On physical functioning, female patients scored lower than female and male spouses $(p<0.001$ for both). On role limitations because of physical problems, female and male patients scored significantly lower than male spouses $(p=$ 0.003 and $p=0.005$, respectively). On vitality, female patients scored significantly lower than male spouses $(p<$ 0.001). Finally, on general health perception, female patients scored significantly lower than male spouses $(p=$ 0.003 ), and male patients scored significantly lower than female and male spouses ( $p=0.004, p<0.001$, respectively).

Time since diagnosis did not correlate significantly with patients' QoL. Time since diagnosis correlated weakly with spouses' physical summary score $(r=0.19, p=0.031)$. Patients with a recurrence scored clinically relevantly lower than patients without recurrence on the physical summary score $(t=3.44, \mathrm{ES}=0.82, p=0.001)$, social functioning $(t=$ 3.12, $\mathrm{ES}=0.79, p=0.003$ ), role limitations because of physical problems $(t=3.72, \mathrm{ES}=0.72, p<0.001)$, and general health perception $(t=3.69, \mathrm{ES}=0.82, p=0.001)$. Spouses of patients with a recurrence scored clinically relevantly lower than spouses of patients without a recurrence on the psychosocial summary score $(t=2.23$, $\mathrm{ES}=0.94, p=0.027)$ and the subscales: role limitations because of emotional problems $(t=2.72, \mathrm{ES}=0.78, p=$ $0.009)$, vitality $(t=3.56, \mathrm{ES}=0.69, p<0.001)$, and general health perception $(t=2.19, \mathrm{ES}=0.52, p=0.033)$.

Treatment intensity was significantly related to patients' QoL. Patients who received intense treatment scored clinically relevantly lower than patients who received nonintense treatment on the physical summary score $(t=2.81$, $\mathrm{ES}=0.79, p=0.004)$ and the following six subscales: physical functioning $(t=2.32, \mathrm{ES}=0.69, p=0.02)$, social functioning $(t=2.33, \mathrm{ES}=0.76, p=0.02)$, role limitations because of physical problems $(t=2.95$, ES $=0.68, p=0.006)$, vitality $(t=3.03, \mathrm{ES}=0.81, p=0.003)$, pain $(t=3.19, \mathrm{ES}=0.78$, $p=0.016)$, and general health perception $(t=2.60, \mathrm{ES}=0.69$, 
Table 2 Descriptives of the RAND-36 scores by parents' gender and health status and comparison between groups and with the norm group

\begin{tabular}{|c|c|c|c|c|c|c|c|c|c|c|c|c|}
\hline & \multirow[t]{2}{*}{ Gender } & \multicolumn{4}{|l|}{ Patient } & \multicolumn{4}{|c|}{ Partner } & \multirow{2}{*}{$\begin{array}{l}\text { Health status and } \\
\text { gender } \\
\text { ANOVA } F\end{array}$} & \multicolumn{2}{|l|}{ Norm } \\
\hline & & Mean & SD & $\begin{array}{l}t(\mathrm{v} . \\
\text { norm })\end{array}$ & $\begin{array}{l}\text { Effect } \\
\text { size }\end{array}$ & Mean & SD & $\begin{array}{l}t(\mathrm{v} . \\
\text { norm })\end{array}$ & $\begin{array}{l}\text { Effect } \\
\text { size }\end{array}$ & & Mean & SD \\
\hline \multirow{2}{*}{$\begin{array}{l}\text { Physical } \\
\text { functioning }\end{array}$} & female & 76.1 & 22.2 & -2.12 & 0.20 & 91.9 & 14.9 & 4.29 & 0.75 & \multirow[t]{2}{*}{12.99} & 80.7 & 23.6 \\
\hline & male & 77.3 & 22.0 & -1.96 & 0.33 & 89.1 & 16.9 & 2.44 & 0.27 & & 84.5 & 22.3 \\
\hline \multirow{2}{*}{$\begin{array}{l}\text { Social } \\
\text { functioning }\end{array}$} & female & 78.5 & 24.4 & -3.16 & 0.31 & 74.7 & 15.9 & -4.17 & 0.71 & \multirow[t]{2}{*}{4.28} & 86.1 & 20.9 \\
\hline & male & 72.6 & 28.4 & -3.31 & 0.56 & 85.6 & 21.7 & 1.29 & 0.13 & & 88.4 & 19.6 \\
\hline \multirow{2}{*}{$\begin{array}{l}\text { Role limitations- } \\
\text { physical }\end{array}$} & female & 64.9 & 41.2 & -3.44 & 0.33 & 84.2 & 29.1 & 1.19 & 0.20 & \multirow[t]{2}{*}{7.20} & 78.3 & 36.5 \\
\hline & male & 57.4 & 45.6 & -3.13 & 0.53 & 81.6 & 35.0 & 0.03 & 0.00 & & 81.5 & 33.6 \\
\hline \multirow{2}{*}{$\begin{array}{l}\text { Role limitations- } \\
\text { emotional }\end{array}$} & female & 79.3 & 35.6 & 0.98 & 0.09 & 81.9 & 33.9 & -0.09 & 0.02 & \multirow[t]{2}{*}{1.45} & 82.5 & 33.5 \\
\hline & male & 83.8 & 32.9 & -0.62 & 0.11 & 87.8 & 28.9 & 0.16 & 0.02 & & 87.3 & 29.3 \\
\hline \multirow[t]{2}{*}{ Mental health } & female & 72.5 & 16.8 & -1.82 & 0.18 & 74.6 & 14.8 & -0.36 & 0.06 & \multirow[t]{2}{*}{2.96} & 75.5 & 18.9 \\
\hline & male & 78.5 & 14.5 & -0.37 & 0.06 & 77.9 & 16.0 & -0.89 & 0.09 & & 79.4 & 17.3 \\
\hline \multirow[t]{2}{*}{ Vitality } & female & 58.8 & 21.8 & -3.63 & 0.34 & 63.8 & 17.6 & -0.84 & 0.14 & \multirow[t]{2}{*}{6.54} & 66.3 & 19.6 \\
\hline & male & 56.9 & 21.4 & -3.07 & 0.59 & 69.1 & 18.7 & -0.23 & 0.02 & & 69.5 & 20.5 \\
\hline \multirow[t]{2}{*}{ Pain } & female & 81.6 & 21.5 & -0.78 & 0.07 & 85.3 & 18.3 & -1.69 & 0.29 & \multirow[t]{2}{*}{2.34} & 80.0 & 25.4 \\
\hline & male & 80.4 & 24.6 & 0.66 & 0.11 & 87.7 & 19.2 & 2.14 & 0.23 & & 83.2 & 23.8 \\
\hline \multirow[t]{2}{*}{ General health } & female & 66.3 & 21.9 & -2.25 & 0.24 & 74.8 & 15.3 & -1.27 & 0.22 & \multirow[t]{2}{*}{8.71} & 71.5 & 21.8 \\
\hline & male & 58.5 & 25.9 & -2.92 & 0.49 & 75.3 & 18.7 & -1.92 & 0.21 & & 71.4 & 23.3 \\
\hline \multirow{2}{*}{$\begin{array}{l}\text { Physical } \\
\text { summary }\end{array}$} & female & 47.2 & 9.8 & - & - & 49.7 & 10.2 & - & - & \multirow[t]{2}{*}{11.38} & Not available & \\
\hline & male & 44.9 & 11.4 & - & - & 50.3 & 9.8 & - & & & Not available & \\
\hline \multirow{2}{*}{$\begin{array}{l}\text { Psychosocial } \\
\text { summary }\end{array}$} & female & 49.7 & 10.2 & - & - & 53.6 & 8.6 & - & - & \multirow[t]{2}{*}{2.31} & Not available & \\
\hline & male & 44.9 & 11.4 & - & - & 52.2 & 8.5 & - & - & & Not available & \\
\hline
\end{tabular}

$p$ values were corrected for multiple comparisons.

Significant values are shown in italics: $p \leq 0.0015$ for comparisons with the norm; $p \leq 0.005$ for comparisons of health status and gender.

$p=0.01$ ). Treatment intensity was not significantly related to spouses' QoL.

Type of cancer had a statistically significant effect on patients' QoL as summarized in Table 3. Statistically significant differences between patient groups were found on the physical summary scale and five subscales. Patients with skin cancer reported the highest QoL. One third of skin cancer patients received intense treatment. Patient with hematological cancer reported the lowest QoL levels. All 16 hematological cancer patients received intense treat-

Table 3 Descriptives of the patients' RAND 36 scores by type of cancer and comparisons between groups

\begin{tabular}{|c|c|c|c|c|c|c|c|c|c|c|c|c|c|}
\hline & \multirow{2}{*}{\multicolumn{2}{|c|}{$\begin{array}{l}\text { Gynecological } \\
\text { tumors } \\
N=16\end{array}$}} & \multirow{2}{*}{\multicolumn{2}{|c|}{$\begin{array}{l}\begin{array}{l}\text { Breast } \\
\text { cancer }\end{array} \\
\mathrm{N}=86\end{array}$}} & \multirow{2}{*}{\multicolumn{2}{|c|}{$\begin{array}{l}\begin{array}{l}\text { Urological } \\
\text { tumor }\end{array} \\
N=10\end{array}$}} & \multirow{2}{*}{\multicolumn{2}{|c|}{$\begin{array}{l}\text { Soft tissue/ } \\
\text { bone }\end{array}$}} & \multirow{2}{*}{\multicolumn{2}{|c|}{$\begin{array}{l}\text { Hematological } \\
N=16\end{array}$}} & \multirow{2}{*}{\multicolumn{2}{|c|}{$\begin{array}{l}\text { Dermatological } \\
N=15\end{array}$}} & \multirow{3}{*}{$\begin{array}{l}\text { ANOVA } \\
F\end{array}$} \\
\hline & & & & & & & & & & & & & \\
\hline & $M$ & SD & $M$ & SD & $M$ & SD & $M$ & SD & $M$ & SD & $M$ & SD & \\
\hline Physical functioning & 78.1 & 17.1 & 78.5 & 20.4 & 81.0 & 14.7 & 59.5 & 15.7 & 57.8 & 32.1 & 88.3 & 15.8 & 5.21 \\
\hline Social functioning & 77.3 & 17.2 & 79.2 & 23.3 & 72.5 & 22.7 & 70.0 & 25.8 & 54.7 & 35.9 & 96.7 & 9.9 & 5.34 \\
\hline Role limitations - physical & 64.0 & 43.8 & 68.3 & 39.9 & 62.5 & 11.5 & 32.5 & 33.4 & 31.2 & 43.3 & 86.7 & 28.1 & 4.61 \\
\hline Role limitations - emotional & 91.7 & 25.8 & 79.5 & 34.7 & 96.7 & 10.5 & 76.7 & 41.7 & 60.4 & 42.5 & 100.0 & 00.0 & 3.16 \\
\hline Mental health & 73.0 & 15.0 & 73.6 & 16.5 & 77.6 & 16.4 & 69.5 & 25.9 & 74.5 & 17.7 & 76.0 & 13.8 & 0.29 \\
\hline Vitality & 60.6 & 17.6 & 58.9 & 20.7 & 58.5 & 24.3 & 52.0 & 16.9 & 43.4 & 28.7 & 77.3 & 18.8 & 4.18 \\
\hline Pain & 86.9 & 17.6 & 81.7 & 21.9 & 75.9 & 19.1 & 60.6 & 20.9 & 73.6 & 29.2 & 92.8 & 13.9 & 3.44 \\
\hline Gen. health perception & 72.8 & 16.0 & 64.9 & 23.1 & 61.0 & 21.6 & 54.5 & 17.9 & 47.2 & 28.2 & 85.7 & 9.8 & 5.79 \\
\hline Physical summary & 78.1 & 17.11 & 78.5 & 20.4 & 81.0 & 14.7 & 59.5 & 15.7 & 57.8 & 32.1 & 88.3 & 15.8 & 6.48 \\
\hline Psychosocial summary & 77.3 & 17.2 & 79.2 & 23.3 & 72.5 & 22.7 & 70.0 & 25.8 & 54.7 & 35.9 & 96.7 & 9.9 & 2.95 \\
\hline
\end{tabular}

$p$-values were corrected for multiple comparisons. Significant values are shown in italics: $p \leq 0.005$ 
ment. A Kruskall-Wallis test confirmed these findings. With regard to the spouses, QoL did not vary as a function of the patient's type of cancer.

Functionality of patient in relation to functionality of spouse

Spouses' psychosocial functioning was moderately strongly related to patients' psychosocial functioning ( $r=0.44, p<$ $0.001)$ and weakly related to patients' physical functioning $(r=0.29, p<0.001)$. No significant relationship was found between the spouse's physical functioning and the patient's psychosocial $(r=0.06)$ or physical functioning $(r=0.07)$.

Relationship between patient and spouse's functioning and emotional and behavioral functioning of the children

Patients' physical functioning was not significantly related to their elementary school-aged children's functioning but was weakly related to the adolescents' total problems and internalizing as reported by the patients (Table 4). Patients' psychosocial functioning was moderately strongly to weakly related to their elementary school-aged children's internalizing, externalizing, and total problems and weakly related to the adolescents' internalizing, externalizing, and total problems as reported by the patient. The patients' physical and psychosocial functioning was moderately strongly to weakly related to the adolescents' internalizing and total problems according to adolescents' self-reports; their physical functioning was weakly related to adolescents' externalizing.

Spouses' psychosocial and physical functioning was not found to be significantly related to their elementary school-aged children's functioning as reported by the spouses. Additionally, their physical functioning was not significantly related to the adolescents' functioning. Spouses' psychosocial functioning was weakly related to the adolescents' internalization and total problems as reported by the spouses. Finally, the spouses' psychosocial functioning was weakly related to the adolescents' internalizing as reported by the adolescents (Table 4).

\section{Discussion}

The aim of this study was to gain insight into the QoL of cancer patients in the child-rearing stage and their spouses. We found that cancer patients $1-5$ years after diagnosis evaluate their QoL as clinically relevantly and/or statistically significantly lower than the normal population on three of the eight domains, partially supporting our first hypothesis. This is in line with studies that have reported a decrease in patients' social and physical domains [7, 9]. However, our study did not find a decrease in patient's emotional functioning, in contrast to some reports $[3,4$, 16]. Our study focused on a subgroup of cancer patients, namely those who are relatively young. The finding that our patient group scored similarly to the norm seems to indicate that these patients' lives have gotten fairly back to normal. These parents seem to be handling the unexpectedness of a cancer diagnosis during this life phase, the treatment, or the confrontation with a possible death at an early age, coupled with the responsibility of raising children fairly well. However, they still seem to experience problems in some areas, specifically social functioning, role limitations because of physical problems, and vitality.

Spouses of cancer patients reported a QoL comparable to the norm group, and female spouses reported even better

Table 4 Correlations between parents QoL, as measured by RAND-36 composite scores, and children's functioning by age group as reported by parents (CBCL) and adolescents themselves (YSR)

\begin{tabular}{|c|c|c|c|c|}
\hline & \multicolumn{2}{|l|}{ Patient $(N=162)$} & \multicolumn{2}{|l|}{ Spouse $(N=150)$} \\
\hline & Physical functioning & Psychosocial functioning & Physical functioning & Psychosocial functioning \\
\hline \multicolumn{5}{|c|}{ Elementary school-aged children (CBCL) } \\
\hline Total & -0.05 & $-0.33 * *$ & -0.19 & -0.11 \\
\hline Internalization & -0.03 & $-0.36^{* *}$ & -0.19 & -0.17 \\
\hline Externalization & -0.03 & $-0.26^{* *}$ & -0.16 & -0.05 \\
\hline \multicolumn{5}{|c|}{ Adolescents (CBCL) } \\
\hline Total & $-0.18 * *$ & $-0.24 * *$ & -0.11 & $-0.22 * *$ \\
\hline Internalization & $-0.19 * *$ & $-0.23 * *$ & -0.15 & $-0.27 * *$ \\
\hline Externalization & -0.10 & $-0.21 * *$ & -0.09 & -0.09 \\
\hline \multicolumn{5}{|c|}{ Adolescents (YSR) } \\
\hline Total & $-0.32 * *$ & $-0.29 * *$ & -0.11 & -0.15 \\
\hline Internalization & $-0.31 * *$ & $-0.32 * *$ & -0.11 & $-0.19^{*}$ \\
\hline Externalization & $-0.20 *$ & -0.13 & -0.09 & -0.02 \\
\hline
\end{tabular}

$* p<0.05$

$* * p<0.01$ 
physical functioning than the norm. Only on one subscale (social functioning) did spouses (and then only women) report decreased functioning. Our findings largely negate our hypothesis and are in contrast with other studies where spouses have reported a decreased QoL [27]. An explanation for our findings may be that spouses in other studies, where the average age is higher, may have had a lower QoL simply because of their older age. As age increases, QoL scores decrease [33]. A second explanation could be that spouses viewed their QoL relative to their ill partner and therefore regarded their own health as good as or better than people generally may. It is also possible that we did not find a decreased QoL in the spouses because our patient group ranged from 1 to 5 years after diagnosis; time since diagnosis correlated significantly positively with spouses' physical functioning. The threat that the patient might not survive may be less prominent for spouses at this point in time.

Our study found significant effects of gender and health status on the physical summary score and four of the eight subscales. To summarize our findings, patients scored lower than spouses, male spouses reported the highest QoL, and, on some scales, the female patient reported the lowest QoL and, on others, the male patient. In a study on gastrointestinal cancer, female patients and female spouses were both reported to suffer overall more distress than male patients [30], which our study did not find. They also reported that female spouses reported lower QoL than male patients and spouses. However, that study examined patients within 6 months after surgery. They also focused specifically on patients with gastrointestinal cancer, which is equally prevalent in men and women. That allowed them to more easily generalize that the differences they found were due to gender. As our study sample was diagnostically heterogeneous, it is difficult to differentiate whether the observed differences were due to gender or cancer site and consequent treatment received. Our study sample consisted of $78 \%$ women, which could seem skewed. However, according to the Dutch Comprehensive Cancer Center's database, cancer occurs more frequently in women during this age range; approximately $65 \%$ of cancer patients in this region of The Netherlands with invasive tumors are women [12].

To further explore our second aim, we analyzed QoL as a function of type of cancer and found differences depending on the type of tumor the patient had, supporting our hypothesis. Skin cancer patients in our study reported the highest QoL, while patients with hematological cancer reported the lowest QoL. These differences may be related to the kind of treatment the patient received. We found that patients who received nonintense treatment reported a better QoL than those who received intense treatment. The removal of a localized melanoma that only requires outpatient excision may affect QoL less than frequent and long hospital stays for courses of chemotherapy for hematological malignancies. Our findings are similar to another study reporting patient distress levels [40] that found that distress levels varied depending on cancer site. With regard to how spouses function, no significant QoL differences were found because of the type of cancer or treatment intensity. It would seem that tumor type or treatment intensity do not affect spouses' functioning. Whether the patient had a recurrence does seem to affect spouses' QoL; the ES of the psychosocial summary score was strikingly large. This may be due to, for those spouses, the still current threat that the patient may not survive. It is interesting to note that recurrence seems to have affected patients' physical and social functioning but not their mental functioning. Patients with recurrence do not report more mental distress than patients who have not had a recurrence.

Thirdly, we investigated relationships between patient and spouse QoL and found weak to moderate positive relationships between cancer patient's physical and psychosocial functioning and spouse's psychosocial functioning. These findings are in line with two studies reporting a moderate positive relationship between patients' and spouses' psychological distress $[9,18]$.

Finally, the hypothesis that we would find a significant relationship between the parents' and the children's' functioning was supported, although the relationships were not strong. The patient's QoL related more often significantly with the children's functioning than the spouse's. Given that four of five of the patients were women, it could be that mothers were more often alert to possible problems in the children than fathers. This may be due to the large number of families in our sample where the mother, sick or healthy, is the primary caregiver. Mothers tend to orient themselves more toward others, whereas fathers tend be more self-oriented [18]; this could enable mothers to judge problems better. It is possible that illness plays a role in the patients' reports as distressed parents are likely to rate more behavioral and emotional problems in their children [22]. However, we found significant relationships between the adolescents' self-reports and parents' functioning. Unfortunately, the cross-sectional design of this study limits us in understanding the causal nature of this finding.

We found more significant, negative correlations with the children's internalizing and total problem scores than externalizing. It would seem that parents' QoL negatively relates to the children's emotional functioning, more than to their acting up. It is interesting to note that the parents' functioning related differently to adolescents and schoolaged children. The patient's physical functioning correlated weakly with the adolescents' functioning but not significantly with the younger children's functioning. This was not found for spouses - their physical functioning did not 
relate significantly to how children from either age group function. Patient's psychosocial functioning correlated weakly to moderately strongly with children in both age groups, while spouses' psychosocial functioning correlated weakly with the adolescents' functioning. Adolescent selfreports provided a similar picture; we found weak to moderately strong correlations between patients' physical and psychosocial functioning but only one weak correlation between spouses' psychosocial functioning and adolescents' internalization. Our finding that parents' functioning related more often significantly with the adolescents may be due to adolescents' stage of cognitive development. Adolescents are more able to understand the patient's illness and may pick up on physical problems more than elementary school-aged children [15].

\section{Research considerations}

In our investigation, being the first to evaluate family functioning in families in the child-rearing age, we purposely did not choose a homogenous cancer group (i.e., only breast cancer). Our results are statements for the general group of child-rearing families with cancer. Comparisons between patients in our research group with varying diagnoses showed differences between groups; however, the small subgroups make it difficult to generalize our findings. Future research will be required to investigate the effect of varying forms of cancer, the stage of cancer, its prognosis, and treatment on the functioning of individual family members.

Additionally, our response rate of $44 \%$ could mean that despite the fact that no differences were found between participants and nonparticipants in gender, type of cancer, or time since diagnosis, a sample bias may exist. We cannot be sure whether psychological problems were over- or underreported; some nonrespondents stated still being overwhelmed by the illness as a reason for not participating, while others indicated they had moved on. Additionally, the cross-sectional nature of this study makes it impossible to accurately capture the dynamic processes present in family relationships or determine whether parents' QoL effects the children's functioning or vice versa. Furthermore, a longitudinal study could provide insight into the QoL of cancer patients and their family members over a period of time. This study found significant relationships between patient and spouse functioning and between parent's functioning and children's behavior. However, these relationships appeared to have modest predictive power. The patients' and spouses' functioning is likely more influenced by other factors not measured in this study, such as personality, social support, or family environment $[19,26]$.

In conclusion, cancer patients' QoL 1-5 years after diagnosis seems to be returning to normal, except in three domains. Their spouses seem to be doing well. The patients' QoL varied according to the type of cancer, how intense their treatment had been, and whether they had experienced a recurrence. Spouses' QoL seemed to be unaffected by the type of cancer and treatment intensity but did vary depending on whether the patient experienced a recurrence. A moderate positive relationship was found between the patient's functioning and his/her spouse's. Parents' physical and psychosocial functioning was weakly to moderately strongly related to their children's functioning. The patients' functioning related more strongly to the children's functioning than the spouses' did. How cancer patients' families function may have an impact on the patient's functioning, up to 5 years after diagnosis. This is something that should be taken into account by clinicians.

Acknowledgments This study was supported by the Dutch Cancer Society (grant no. 2000-2333) and the Ijsselmond Foundation for Health Care Research.

\section{References}

1. Achenbach T (1991) Manual for the Child Behavior Checklist and 1991 profiles. University of Vermont, Department of Psychiatry, Burlington, VT

2. Achenbach T (1991) Manual for the Youth Self Report and 1991 profiles. University of Vermont, Department of Psychiatry, Burlington, VT

3. Arndt V, Merx H, Stegmaier C, Ziegler H, Brenner H (2005) Quality of life in patients with colorectal cancer 1 year after diagnosis compared with the general population: a populationbased study. J Clin Oncol 22:4829-4836

4. Avis N, Crawford S, Manuel J (2005) Quality of life among younger women with breast cancer. J Clin Oncol 23:3322-3330

5. Baider L, Kaufman B, Peretz T (1996) Mutuality of fate: adaptation and psychological distress in cancer patients and their partners. In: Baider L, Cooper C, Kaplan-De Nour A (eds) Cancer and the family. Wiley, New York, pp 173-186

6. Baider L, Walach N, Perry S, Kaplan-De Nour A (1998) Cancer in married couples: higher or lower distress? J Psychosom Res 45:239-248

7. Bardwell W, Major J, Rock C, Newman V, Thomson C, Chilton J, Dimsdale J, Pierce J (2004) Health-related quality of life in women previously treated for early-stage breast cancer: for the women's healthy eating and living (WHEL) study group. Psychooncology 13:595-604

8. Brooke R, Ware J, Davies-Avery A, Stewart A, Donald C, Rogers W, Williams K, Johnston S (1979) Overview of adult health status measures fielded in RANDS's Health Insurance Study. Med Care 15:724-735

9. Cimprich B, Ronis D, Martinez-Ramos G (2002) Age at diagnosis and quality of life in breast cancer survivors. Cancer Pract 10: 85-93

10. Cohen J (1988) Statistical power analysis for the behavioral sciences (rev. ed.). Erlbaum, Hillsdale, NJ

11. Comprehensive Cancer Center. Cancer incidence in the Netherlands. http://www ikcnet nl/page php?id=160 2006 February 4

12. Comprehensive Cancer Center. Cancer incidence in the Netherlands by gender. http://www ikcnet nl/uploaded/FILES/Landelijk/cijfers/ Incidentie\%202003/A4\%201999-2003 xls 2006 July 24 
13. Edwards B, Clarke V (2004) The psychological impact of a cancer diagnosis on families: the influence of family functioning and patients' illness characteristics on depression and anxiety. Psychooncology 13:562-576

14. Fang C, Manne S, Pape S (2001) Functional impairment, marital quality and patient psychological distress as predictors of psychological distress among cancer patients' spouses. Health Psychol 20:452-457

15. Faulkner R, Davey M (2002) Children and adolescents of cancer patients: the impact of cancer on the family. Am J Fam Ther 30:63-72

16. Ganz P, Greendale G, Petersen L, Kahn B, Bower J (2003) Breast cancer in younger women: reproductive and late health effects of treatment. J Clin Oncol 21:4184-4193

17. Hodges LJ, Humphris G, Macfarlane G (2005) A meta-analytic investigation of the relationship between the psychological distress of cancer patients and their carers. Soc Sci Med 60:1-12

18. Hoekstra-Weebers J, Jaspers J, Kamps W, Klip E (1998) Marital dissatifaction, psychological distress, and the coping of parents of pediatric cancer patients. J Marriage Fam 60:1012-1021

19. Huizinga G, Visser A, van der Graaf W, Hoekstra H, HoekstraWeebers J (2005) The quality of communication between parents and adolescent children in the case of parental cancer. Ann Oncol 16:1956-1961

20. Huizinga GA, Visser A, Hoekstra H, van der Graaf W, Klip E, Pras E, Hoekstra-Weebers J (2005) Stress response symptoms in adolescent and young adult children of parents diagnosed with cancer. Eur J Cancer 41:288-295

21. Keller M, Henrich G, Sellschopp A, Beutel M (1996) Between distress and support: spouses of cancer patients. In: Baider L, Cooper C, Kaplan-De Nour A (eds) Cancer and the family. Wiley, New York, pp 187-223

22. Krain A, Kendall P (2000) The role of parental emotional distress in parent report of children anxiety. J Clin Child Psychol 29:328-335

23. Manne S (1998) Cancer in the marital context: a review of the literature. Cancer Invest 16:188-202

24. Norman G, Sloan J, Wyrwich K (2003) Interpretation of changes in health-related quality of life: the remarkable universality of half a standard deviation. Med Care 41:582-592

25. Northouse LL, Mood D, Templin T, Mellon S, George T (2000) Couples' patterns of adjustment to colon cancer. Soc Sci Med 50:271-284

26. Parker P, Baile W, De Moor C, Cohen L (2003) Psychosocial and demographic predictors of quality of life in a large sample of cancer patients. Psychooncology 12:183-193

27. Pitceathly C, Maguire P (2003) The psychological impact of cancer on patients' partners and other key relatives: a review. Eur J Can 39:1517-1524
28. Rait D, Mederberg M (1990) The family and the cancer patient. In: Holland J, Rowland J (eds) Handbook of psychoonocology. Psychological care of the patient with cancer. Oxford Univ. Press, Oxford, pp 585-597

29. Scott L, Halford W, Ward B (2004) United we stand? The effects of a couple-coping intervention on adjustment to early stage breast or gynecological cancer. J Consult Clin Psychol 72(6):1122

30. Tuinstra J, Hagedoorn M, van Sonderen E, Ranchor A, van den Bos G, Nijboer C, Sanderman R (2004) Psychological distress in couples dealing with colorectal cancer: gender and role differences and intracouple correspondence. Br J Health Psychol 9: $465-478$

31. van der Zee K, Sanderman R (1993) Measurement of general health with the RAND-36 (Het meten van de algemene gezondheidstoestand met de RAND-36: een handleiding). Noordelijk Centrum voor Gezondheidsvraagstukken, Groningen, The Netherlands

32. van der Zee K, Sanderman R, Heyink J (1996) A comparison of two multidimensional measures of health status: the Nottingham Health Profile and the RAND 36-item Health Survey. Qual Life Res 5:165-174

33. van der Zee K, Sanderman R, Heyink J, Haes H (1996) Psychometric qualities of the RAND 36-item 1.0: a multidimensional measure of general health status. Int J Behav Med 3:104122

34. Verhulst F, van der Ende J, Koot H (1996) Manual for the child behavioral checklist. Erasmus University, Department of Child and Adolescent Psychiatry, Rotterdam, The Netherlands

35. Verhulst F, van der Ende J, Koot H (1996) Manual for the youth self report. Erasmus University, Department of Child and Adolescent Psychiatry, Rotterdam, The Netherlands

36. Visser A, Huizinga G, Hoekstra H, van der Graaf W, Klip E, Pras E, Hoekstra-Weebers J (2005) Emotional and behavioural functioning of children of a parent diagnosed with cancer: a crossinformant perspective. Psychooncology 14:1-12

37. Walsh F (1988) The family in later life. In: Carter B, McGoldrick M (eds) The changing family life cycle. Allyn and Bacon, Boston, MA, pp 311-334

38. Ware J, Kosinski M (1994) SF-36 physical and mental health summary scales: a user's manual. The Health Institute, Boston, MA

39. Wenzel LB, Fairclough D, Brady M, Cella D, Garret K, Kluhsman B, Crane L, Marcus A (1999) Age-related differences in the quality of life of breast carcinoma patients after treatment. Cancer $86: 1768-1774$

40. Zabora J, Brintenhofeszoc K, Curbow B, Hooker C, Piantadosi S (2001) The prevalence of psychological distress by cancer site. Psychooncology 10:19-28 